\title{
A Customized e-Shopping System for SMEs in Developing Countries: Cases from the sub Saharan Desert of Africa
}

\author{
E. A. Olajubu, B. S. Afolabi and A. O. Ajayi
}

\begin{abstract}
There are a myriad of problems facing developing nations' SMEs among which is the lack of institutional infrastructures for ICT adoption and usage. This paper tailors an existing e-Shopping model to the peculiar needs of SMEs in sub Saharan desert of Africa with a view to enter and participate in the competitive global market for goods and services. Various issues affecting the development and implementation of e-Shopping for developing nations' businesses were identified. Solutions to these shortcomings are proposed, and an easy way of developing e-Shopping for developing nations' SMEs is presented. A model that signifies the digital divide between multi-national and SMEs in developing nations is also presented.
\end{abstract}

Index Terms-ICT, Infrastructure, Internet, Market Coverage, SMEs, sub Saharan Africa.

\section{INTRODUCTION}

E lectronic shopping - the business-to-customers dimension of electronic commerce is defined as a system that enables users to purchase commodities through computer networks such as the Internet. It provides products and services customisation, in contrast to buying in a store or ordering from a television advertisement, which is usually limited to standard products [6]. e-Commerce, a subset of e-Business, is the purchasing, selling, and exchanging of goods and services over computer networks (such as the Internet) through which transactions or terms of sale are performed electronically [15]. e-Business refers to any business that uses Information Communication and Technology (ICT) infrastructure or Internet technology to improve business deliverables. The deliverables can be in terms of productivity, sales of goods and services, profit, etc. A business that uses

Manuscript received July 4, 2009. Accepted November 21st, 2009.

E. A. Olajubu is with the Department of Computer Science and Engineering, Obafemi Awolowo University, Ile-Ife, Nigeria (e-mail: emmolajubu@oauife.edu.ng).

B. S. Afolabi and A. O. Ajayi are also with the Department of Computer Science and Engineering, Obafemi Awolowo University, Ile-Ife, Nigeria (e-mail: bafox@oauife.edu.ng, anuajayi@oauife.edu.ng).
Internet to purchase wholesale products is referred to as e-Procurement while e-Shopping also referred to as online shopping allows the use of Internet to purchase goods for an individual. e-Market which encapsulates e-Shopping, e-Retailing, e-Payment, etc. is a subset of e-Business which has removed the distance barrier, thereby increasing global competition among goods and service providers. While the multinationals have the advantage of large scale production and better funding, they possess the wherewithal to secure ICT equipment that will project and promote the sale of their products beyond the borders of their nations throughout the world using the Internet. This allowed infiltration of goods and services from advanced economies into many developing nations' markets. While it is advantageous in terms of quality of products, it has undermined the development of SMEs in these nations. The SMEs which dominate emerging nations' economies do not have a global competitive advantage with either their counterpart SMEs in developed nations or with super companies in the world market. The peculiar problem facing SMEs in developing countries is that of ICT infrastructures provisioning. ICT and e-Business models have become the major drivers of business innovation and global competitiveness as the world become a global village. Lack of involvement of developing nations' SMEs in the global competitiveness has put them in great disadvantage as they lacked world class cutting edge researches and business initiatives which can improve the quality of their products and services. It is very difficult to find researches sponsored by "large" SMEs; this is due to little or no challenge for improvement in goods and services delivery. Consequently, SMEs in developing countries have remained in their traditional way of goods and services provisioning, and delivery which has not encouraged economic growth nor fostered realistic national development. To address the aforementioned problems in the subSaharan region of Africa, we tailored an e-Business model towards the needs of SMEs in the region. The problems facing SMEs in the region are itemised 
and feasible solutions offered so as to encourage SMEs in the region to adopt e-Business transactions [9]. The paper also provides alternative options for e-Payment, where facilities such as credit or debit cards are not available. The rest of the paper is organized as follows: Section on ICT Adoption by SMEs defines SMEs in a developing country context and also discusses the market audience structure; e-Shops and developing countries section elucidates the peculiar problems facing SMEs which do not allow ICT infrastructure usage; section on Basic Web Process Model presents the model architecture and peculiar solution to the problem of e-Commerce adoption by SMEs; Requirements section states users' requirements with some screen shots of the developed system, and finally the conclusion is presented.

\section{ICT AdOPTION By SMEs}

According to [7], SMEs are defined as a very heterogeneous group of businesses usually operating in the service, trade, manufacturing and agro-allied sectors. They include a wide variety of firms such as village handicraft makers, small machine shops, and computer software firms that possess a wide range of sophistication and skills. Some are dynamic, innovative, and growth-oriented while others are satisfied to remain small and perhaps family owned. SMEs usually operate in the formal sector of the economy and employ mainly low-wage earning workers. While e-Commerce is seen as a strong tool that can reduce transaction cost in the international market [10] [12] to a level where SMEs with financial constraint can actively participate, it is disheartening that SMEs in developing countries, for economic and infrastructure reasons are yet to respond positively to ICT adoption [7][11][14]. They lack effective organisation and the working knowledge of modern technologies such as e-Commerce, e-Shopping, e-Business, etc. The major challenge facing SMEs in the utilisation of ICT facilities has been the issue of payment, mostly due to high cost and unavailability of e-Procurement facilities such as credit or debit cards. More so, when and where these facilities are present, the credibility of the facilities is usually very low.

SMEs are often classified by the number of employees and/or by the value of their assets. The size classification varies within regions and across countries relative to the size of the economy and its endowments. It is important to note that there is a minimum as well as a maximum size for SMEs. For instance, in the USA, the small business administration defines 'small business' as any business with less than 500 employees while the UN stipulates a workforce of not more 250 workers [26], SMEs in developing nations may have employees far less than 250, SMEs in sub-Saharan African and other developing nations may even have workforce less than 50[26] [7]. The SMEs which are often household enterprises with narrow financial strength, have denied themselves the advantages of ICT, though they are the major employers of labour in many economies, especially the developing economies [1]. This important segment of economy has been neglected in the deployment of ICT in many developing countries in Africa [2]. The impact of ICT on SMEs in the developed world is immense. In countries such as Australia, the adoption of ICT in the form of e-Business started in the early 1990s when there was Electronic Data Interchange (EDI) provisioning by the government [19]. Improvement in technology and customers' demand for value for money, as well as external factors such as competitive pressures and pressure from business partners [18], ICT infrastructures provisioning by government [19], and presence of ICT constants [20] have encouraged the SMEs to gradually migrate from EDI to e-Business solutions as a means of business leverage [17]. While EDI is predominately used by large organizations, government initiative for ICT provisioning has made SMEs beneficiary. Also, in South Korea, the incorporation of ICT into SMEs started with the adoption of EDI and then moving gradually towards an e-Trade system and paperless trade system which is being encouraged by the government to be used by the widest number of people [25]. The use of ICT has played a crucial role in transforming local economy and bridging productivity gap between the SMEs and the mega factories in Europe which have transferred their goods and services beyond the borders of their nations [23]. It is easy for SMEs in Europe to compete favourably with multi-national companies in the sale of products by exploiting e-Business solutions originally used by mega companies. As a result, many IT solution providers are focusing on software that are SMEs oriented laying down procedures to encourage micro businesses to adopt the use of ICT [16]. This is in contrast to what is available in developing economies of the sub Sahara where SMEs' products are inferior, thereby increasing the difficulty to compete with multi-national companies' products. In Thailand, ICTs have been adopted by a Leather Company to improve market sales and to gain competitive advantage. This has improved the quality of the products and has expanded their market share within Thailand. However, it is still difficult for the company's product to compete favorably with leather products from China [24]. The challenges of SMEs in developed economies are quite different from what the SMEs in developing nations are facing [22], the developing nations SMEs are faced with lack of basic infrastructures 
that can improve business-to-business and business-to-customer relationship. In any business environment, customers are king. It is incumbent on the business to find means of satisfying her customer so as to retain or increase her market share. Many customers want value for their money in terms of quick and reliable service while it is the duty of business management to find appropriate means or technology that will guarantee customer satisfaction. Business methodologies and strategies have greatly been influenced in the developed economies in such a way that one can order goods from anywhere (home or office) and have them delivered at one's door step within a few minutes at little or no extra cost. This improved business strategy [13] is very rare in developing countries, and where available, it is owned by the multi-nationals from the developed worlds that have the wherewithal to meet and use the modern "business know-how" of today known as Electronic Commerce (EC).

$\mathrm{EC}$ is an emerging concept that describes the process of buying and selling or exchanging of products, services, and information via computer networks including the Internet. According to [2] $\mathrm{EC}$ is defined from these perspectives:

- From a communications perspective, EC is the delivery of information, products/services, or payments over telephone lines, computer networks, or any other electronic means.

- From a business process perspective, EC is the application of technology towards the automation of business transactions and workflow.

- From a service perspective, EC is a tool that addresses the desire of firms, consumers, and management to cut service costs while improving the quality of goods and increasing the speed of service/delivery.

- From an online perspective, EC provides the capability of buying and selling products and information on the Internet and other online services.

\section{A. Emergence of an e-market}

The origin of commerce through the exchange of goods occurred before recorded history, now commerce is a basic activity of goods trading and buying in everyday life. Entering into the electronic era, the way individuals and organizations do business and undertake commercial transactions have changed. This indicates the movement towards electronic commerce. This means there is no paper work and physical interaction is limited, if at all. The emergence of electronic commerce started in the early 1970s with the earliest example of electronic funds transfer (EFT), which allows organizations to transfer funds between one another electronically.
Then another technology Electronic Data Interchange (EDI) was introduced. It helped to extend interbusiness transactions from financial institutions to other types of business and also provided transactions and information exchanges from suppliers to the end customers. However, the early system development was limited to special networks such as large corporations and financial institutions, which were costly and complex to administer for small business. So EDI was not widely accepted as expected [8].

With the progress in Internet technology and a highly developed global Internet community, a strong foundation of prosperous electronic commerce continues to be built. During the 1990s, the Internet was opened for commercial use; it was also the period that users started to participate in World Wide Web (WWW), and the phenomenon of rapid personal computer (PCs) usage growth. Due to the rapid expansion of the WWW network; e-Commerce software; and the peer business competitions, large number of dot-coms and Internet starts-ups appeared. Integrated with the commercialization of the Internet, Web invention, and PC networks, these three important factors made electronic commerce possible and successful [5][8].

\section{B. Market Coverage Model}

It is a good marketing practice to always compare the effectiveness of the implementation/production of goods and services with that of others to know whether one is at a comparative advantage. Therefore, if a good or service costs more but brings in better sales than other alternatives, emphasis should be placed on this particular good or service.

We present Fig. 1 as the model we have developed to compare the effectiveness of cost against reached audience (distance coverage) in a marketing environment. The more the distance covered the more people that will be reached. In the simple model presented, it can be observed that:

$$
\text { Ratio of } \quad \text { Cost of implementation }
$$

This means, using Euclidan geometry,

Oral Advertisement $=\mathrm{BC} / \mathrm{AC}=\tan \alpha$

Radio-Vision Advertisement $=\mathrm{DE} / \mathrm{AE}=\tan \rho$

Internet Advertisement $=\mathrm{FG} / \mathrm{AG}=\tan \mu$

By observation, in mathematical relationship of trigonometric ratio

$\tan \mu>\tan \rho>\tan \alpha$ 
This implies that there is an increase in geographical coverage as one move from oral advertisement to Internet advertisement due to the number of audiences reached. More so, it is assumed that Internet advertisement covers every one that has access to the Internet anywhere and anytime [21]. The gap between the Internet advertisements and the Oral advertisements or better Radio-Vision advertisements in terms of audiences reached in Fig. 1 signifies the gap between the SMEs in developing nations and the multi-nationals in these nations in terms of market sharing. The Internet serves as a levelling ground for both multi-nationals and SMEs in developing countries, if the SMEs can pull resources together so as to get access to the Internet for their marketing. Therefore, it would be an advantage for SMEs to avail themselves of the offer of Internet. The major problem for these SMEs is the initial capital outlay required for Internet infrastructure and implementation. This is the reason for this discussion.

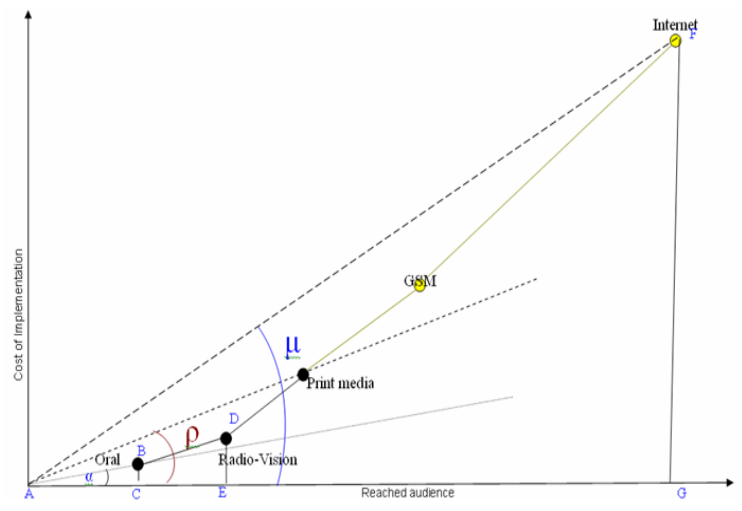

Fig. 1. Market Coverage Model.

\section{III. e-Shops And Developing Countries}

An average e-Shop that is making wares in the developed world may not function with the same aplomb in developing countries. This is due to some peculiarities found in these developing countries. It is a well known fact that a technology that succeeds in one country may not in another. An example is Minitel that worked so well and was so popular that it became an instance success in France which did not quite succeed in some other countries. In most developing countries especially in Africa, there are a number of intimidating problems from availability of infrastructure to bandwidth problems, and even logistics problems.

As one would have noticed, small and medium scale enterprises vary in sizes and capacities from country to country. In most developing nations, majority of these enterprises are made up of just one employee (the owner who gets help once in a while from a member of the family). This is to say that if such a person gets to be able to put his wares on the net (on an e-Shop), it will come as a big relief to him as attending to individual clients who come to shop would no longer be a problem. Such a person could gain enough time to get into other projects. Some of the problems that confront the setting up of an e-Shop in developing countries we encountered in the course of this study include but not limited to:

\section{A. Lack of national or initial infrastructure}

Our country of study is Nigeria, and the first basic thing we encountered was the absence of basic infrastructure like telephone lines (ADSL lines, Vsat, Fibre cables etc.) that could allow a group of SMEs to set up an e-Shop. This factor has contributed greatly to the backwardness of e-Business. At first, this venture did not make an interesting adventure to take as there is no guarantee that the e-Buyers may ever get to see and appreciate the goods on offer. To this effect, the prospects of developing the site became uninspiring.

Eventually, an advert by a GSM operator that it gets up to a million hits per day changed the whole story. It is now a question of making the site as popular as possible in order to get people to start logging on to it.

\section{B. Initial cost of putting up such sites}

As earlier highlighted, the notion of SMEs in developing countries cannot be compared to that of developed nations. The turnover of most SMEs in Developing countries is barely able to pay for hired hands. In fact, most of the SMEs are also seen as family businesses where the business is overseen by a member of the family (and this usually is for free, that is, none paid). So in essence, any extra cost that may come into the business is avoided as much as possible. The initial cost of buying the equipment and other necessary things to get the market started might become prohibitive for the economy of such an SME. In this work, we formulated an e-Shopping platform where a number of SMEs can jointly own a website and different SMEs will own their webpage on the same server mainly for advertisement of goods and services. The server will be jointly owned and will be jointly administered by the group of SMEs. For security purpose, we advised that SMEs should allow Web administrator employed by each to own passwords to the system.

\section{Logistics and distribution}

Distribution of mails or regular posts is one of the most challenging problems in developing countries. There are so many reasons for these: indiscriminate buildings that make addressing 
difficult, irregularities in the functioning of local postal services that make delivery take longer than necessary, transportation problems (e.g. bad roads, inadequate transports, etc.).

\section{Payment methods}

Until recently, most developing nations did not use any other payment facility than cash. The number of residents having access to credit or debit cards was limited and as such the possibility of Internet payments was therefore limited to these privileged few. Therefore, in order that other people may have access to these types of shops other means of payment must be explored.

\section{E. Lack of trust}

In Nigeria in particular, there is a major problem of trust among the citizens. This is a major problem as a minimum level of trust must be displayed between participants of the marketplace. A buyer must have a certain amount of trust that what the seller is selling is what he/she claimed to be selling and the seller must believe that the buyer is giving the right information about himself/herself.

These are few of the challenges facing the SMEs in this region, now we proceed to discuss some of the fundamentals of the web model.

\section{Basic Web Process Model}

According to [4], the most basic process model used in web site development should be familiar to most people, as it is deductive. The basic model starts with the big picture and narrows down to the specific steps necessary to complete the site. In software engineering, this model is often called the software lifecycle model, because it describes the phases in the lifetime of software. For a trade to occur between buyer and seller, a certain process must occur. Fig. 2 depicts the architecture adopted in this study which illustrates the basic processes involved in e-Shopping between a buyer and seller.

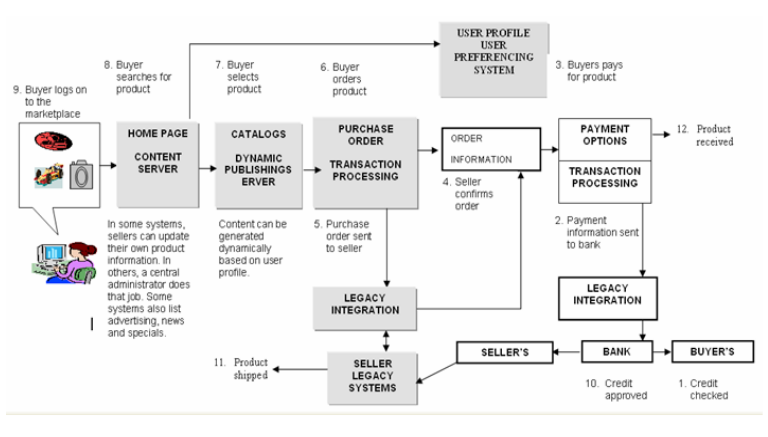

Fig. 2. System Architecture.
A customised electronic shopping system consists of five major services: an e-Buyer agent, an e-Shop for made-to-specification goods, suppliers that stock or manufacture goods to be sold through the e-Shop, shipping agency that ships the ordered goods to the e-Buyer and a payment validation service. From the architectural model, the buyer logs on to the marketplace, through the Universal Resource Locator (URL) of the website, the buyer then searches for the product, when the product has been found, the buyer selects product using the shopping cart, the e-Buyer sends details of its requirements for a particular product to the e-Shop. The e-Shop provides a list of suppliers that can possibly meet those requirements and for which it works as a price - negotiating agent.

The e-Buyer forwards the product specification to the chosen supplier(s), who confirm(s) if it is possible to supply the product. The suppliers forward the costing of the order to the e-Shop. The e-Buyer negotiates the price with the e-Shop and places the order. The supplier contacts a shipping agency about delivering the order. The shipping agency replies with the pickup date. Finally the shipping agency informs the e-Shop and the e-Buyer about the delivery date. The e-Buyer sends a confirmation on receiving the placed order. Since the goods are made-to-specification, cancellation of an order is allowed only within 24 hours of placing the order.

\section{A. Steps in the Electronic Shopping System}

The following illustrates the processes involved in electronic shopping systems. The e-Buyer logs on to the electronic marketplace through several means such as locating the site through an Internet search engine like Google.com, Find.com, and Yahoo.com or by using the Universal Resource Locator (URL) of the e-Shopping site e.g. www.buynow.com. When the e-Buyer is logged on to the e-Shopping website, he/she searches for products by using available category hyperlinks. Some e-Shopping sites also have a search engine facility that enables e-Buyers to search for specific products.

When the e-Buyer is satisfied with a particular product, he/she selects the product into an electronic shopping cart, which is similar to the conventional cart or trolley used in departmental stores. The e-Buyer specifies that the products that have been selected into the shopping cart be sent to the e-Shop for processing. The e-Buyer forwards the product specification to the chosen supplier(s), who confirm(s) if it is possible to supply the product. The e-Shop confirms that the order has been received from the e-Buyer and confirms if the products ordered are available from the manufacturer. The supplier forwards the costing of the order to the e-Shop. The e-Buyer negotiates the price with the 
e-Shop and places the order. The e-Buyer makes his orders by using electronic procurement facilities like credit cards and debit cards. The procurement information supplied by the e-Buyer is sent to a Transaction Handlers Bank (Automated Clearing House) which validates the information supplied by the e-Buyer. The Transaction Handlers Bank checks credit card or debit card information for authentication. If the credit information is authentic, then the Transaction Handlers Bank sends a confirmation to the e-Shop that the credit has been approved. The e-Shop then commences the processing of the order, by sending the e-Buyer's transaction details to the supplier. The supplier contacts a shipping agency about delivering the order. The shipping agency replies with the pickup date.

\section{B. Steps Taken to Correct Peculiar Problems of SMEs in Developing Nations}

Some of the problems with developing countries highlighted in section 3 are so peculiar with developing countries that they need to be solved locally or provide a means of contouring the problems. These problems are either solved or avoided. Some of the problems earlier highlighted are taken care of by using the following:

1. Infrastructural problems are taken care of by hosting the sites outside of the country (i.e. in developed countries). The uploading of the sites could be done from a cyber café or on the ISP server based on negotiations.

2. Hosting of these sites outside of the country may become expensive due to exchange rates and other reasons. In order to take care of this problem, a number of SMEs can come together to host a site so that the cost is spread and borne by all. Another SME could be created to cater for the hosting and the general well being of the site.

3. Distribution and logistic problems can be taken care of by the creation of collection points. This avoids the delays experienced through the use of postal services that are comatose. Collection points are created in each of the major centres/ towns. The goods for each customer are delivered using the nearest collection point to him/her as there can be many collection points in each town depending on the number of customers, and the buying frequency of customers in that town.

4. Until recently no debit or credit cards existed in Nigeria or most of the developing countries. So the method of payments became an issue. With the arrival of debit cards, this problem was reduced but even with that, there are still a quite number of people who do not have access to debit cards. For this category of people, we suggest the use of telephone recharge cards. Since Nigeria is now pervaded with phone cards, the buyer can buy a telephone recharge card of equivalent value as the price of the goods he/she is buying. These credits (recharge cards) can be sent to the seller and (buyer's) goods can then be sent to the collection point nearest to the buyer.

5. The reputation of the individuals hosting the site can serve as a means of avoiding such a problem.

\section{REQUIREMENTS}

Due to some specific problems encountered in developing countries, for instance, in terms of bandwidth availability, the system should be such that it can load as fast as possible with a reduction in the number of images used. We have also reduced the size of the images used. This was done in such a way as not to impair too much the quality of the images but to reduce the resolution of images which in turn will reduce size and considerably, the download time.

Accesses to the Internet have greatly increased with the proliferation of Cyber cafés that are now available in numbers in major cities. This also comes with its attendant problems, most especially cyber crimes. In order to aid the crime fighters as much as possible, the system tracks the IP addresses of the machines that are connected to it from which ever location. Also for now, credit or debit cards will have IP address attached. This is also a cyber crime combating measure. Although this is known to be limiting and inefficient, alternative measures are being explored to reduce frauds.

\section{A. $\quad$ End User Requirements}

The end user would be required to use the application from any web browser supporting HTML 3.2 (or later standard) and cookies, this is due to some of the security features built into it. It is also necessary to uniquely identify each user; therefore each user must register to be able to use the system. Each user registration is therefore a property of the user and he/she takes responsibility of whatever action that takes place.

Security of sensitive information (like scratch card number etc.) is of paramount importance, so the site is built on SSL. The issues involved in this are left out of this write-up. Users are able to search the entire database based on category, on each item, or a keyword. They can change items, quantities, etc., they can also view the status of their order. 


\section{B. End User Interaction with the Shopping Cart Application}

This is a sequence of actions to be carried out by typical users, who visit the web site for shopping. New users coming to the site for the first time will register themselves while existing users will authenticate themselves by providing valid user identity and password. After a successful authentication procedure, the users, can browse product titles, add items to the shopping cart, view the list of items in their cart, change the quantities of items or even delete items selected earlier. When the user has made up his/her mind to buy items in the cart, he/she then checks out. Checking out is the confirmation of user's willingness to buy items in the cart. After the user has checked out, the items in the user's cart are entered in the database, and the items are later shipped to the address of the user given at the time of registration. After checking out, the user can continue shopping or can decide to logout. Users can also browse music and book titles available in the shopping cart site, without purchasing any items. Sometimes users would be interested in viewing the current status of their accounts, and the status of items, (e.g. whether they have been shipped or not), purchased by them earlier. Some of the screen shots of the software are provided below.

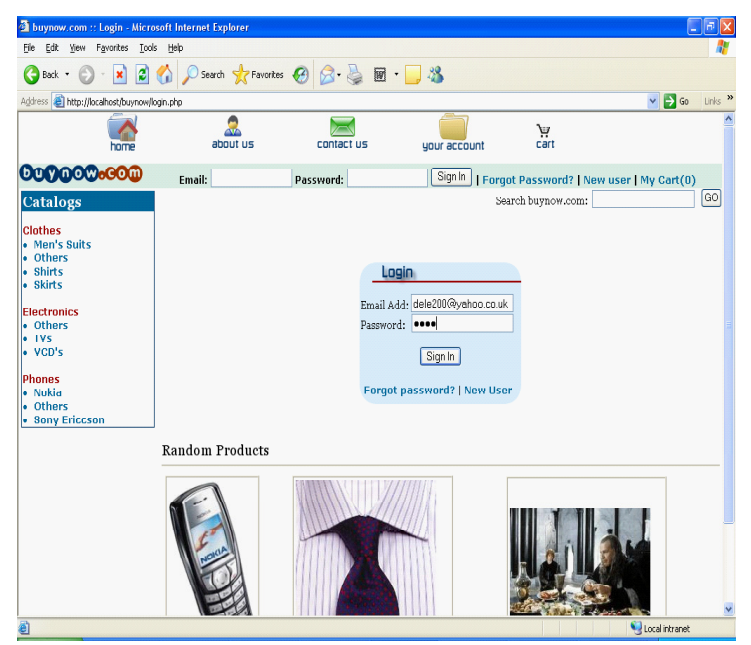

Fig. 3. Screen shot for Goods and Services.

Fig. 3 is the screen shot for the type of services offered at the website, Fig. 4 is the screen shot specifically for GSM phone vendors. Also, Fig. 5 presents a retailer whose goods cut across range of products and lastly Fig. 6 is the screen shot for customers who intend to transact business in the website.
Fig. 3 presents the security information, and also the type of goods and services provided by the website. The password is expected to be owned by the web administrator, who manages the web site.

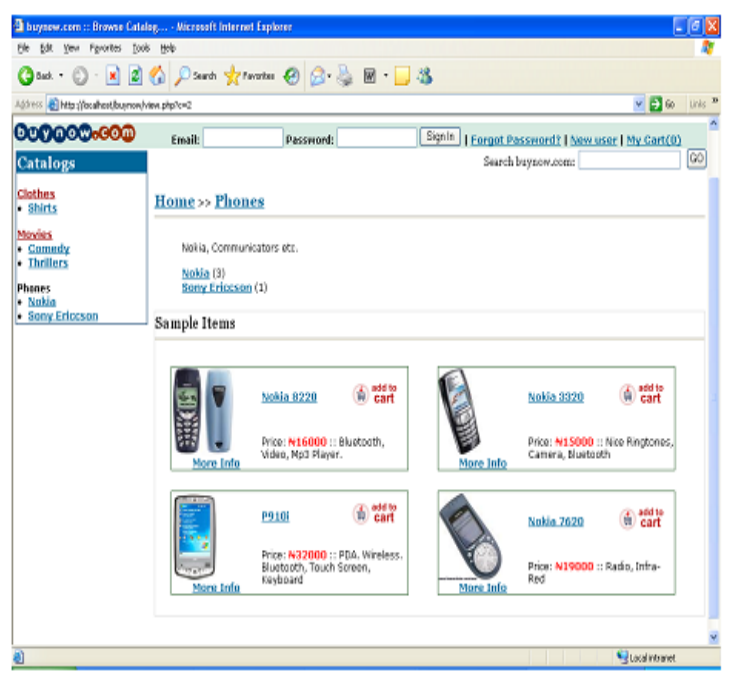

Fig. 4. GSM Phone Vendor Screen shot.

Fig. 4 shows the webpage for mobile phone vendors. There can be multiple of pages depending on the number of GSM phone vendors involved in the e-Shop. A webpage is meant to be owned by a vendor irrespective of the type of phones.

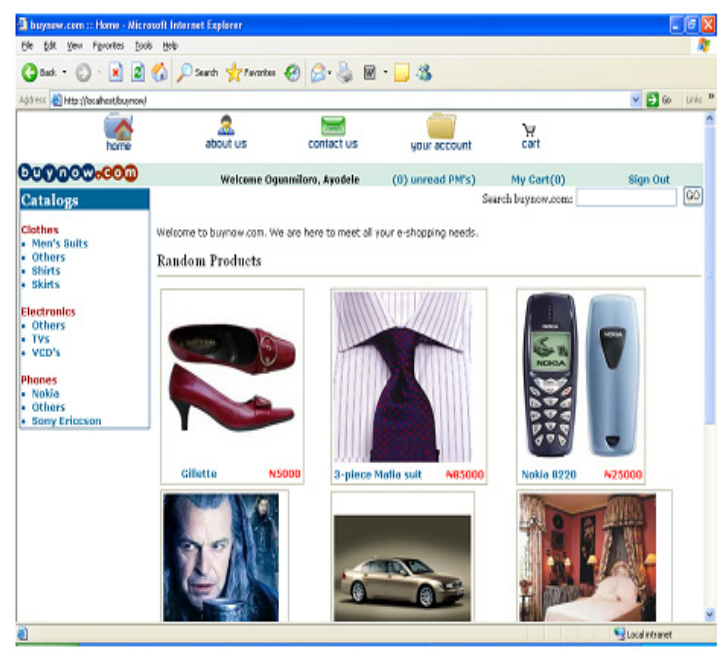

Fig. 5. Vendor with variety of Goods.

Fig. 5 displays some vendors having wares cut across different items. In our environment many retailers have wares from different manufacturers. The main idea is that each vendor has one webpage except those who can afford multiple web pages on the server. 


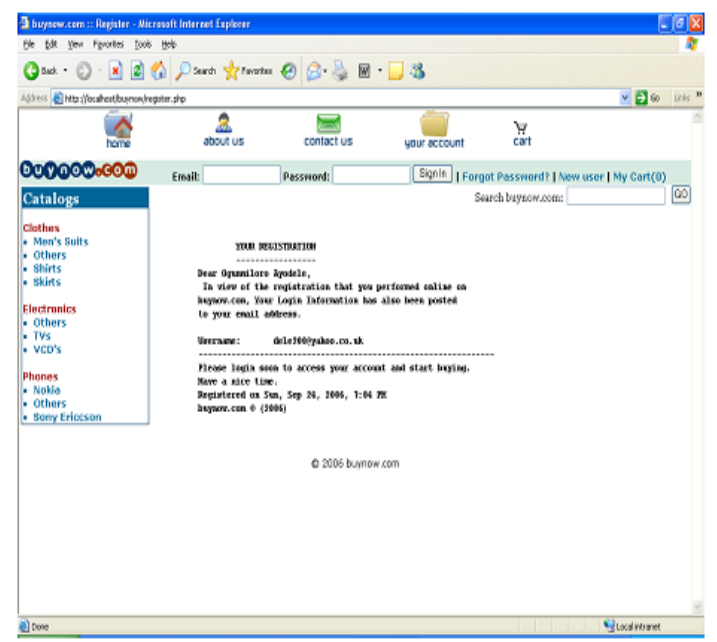

Fig. 6. Registration point for potential customer.

Fig. 6 is meant for customers who intend to buy from the Website. Ordering goods from the website requires that the customers register formally with the website.

\section{CONCLUSION}

This work was carried out with the view of creating an enabling environment for the successful implementation of an e-Shopping system for SMEs in developing countries. The following areas of e-Shopping system have been successfully implemented: New users can be registered; Existing users can login and check their account status, Users can buy products online from our shopping cart application, Users can view a complete list of products available on the shopping cart, Users can search for products online, Users can search the entire database for keywords, they can choose and add products to their cart, and decide later whether they would like to buy the selected products, Users can change the quantities of the items or delete items from their cart, before checking out, Users can view the status of products they have ordered, Large number of users can use the application simultaneously. Majority of the specific problems facing developing nations in terms of use of e-Shops have been addressed.

\section{REFERENCES}

[1] M. Bah, S. Cissé, B. Diyamett, G. Diallo, F. Lerise, D. Okali,E. Okpara E, J. Olawoye and C. Tacoli, Changing rural-urban linkages in Mali, Nigeria and Tanzania Environment\&Urbanization, Vol 15 No 1 April 2003 pp. 13-24.

[2] A. Beyene, Enchaning the competitiveness and productivity of Small and Medium Scale Enterprises (SMEs) in Africa: An Analysis of Differential Roles of National Government Through Improved Support services African Development, vol. XXVII No 3 pp130-156.
[3] R. Kalakota and A. B. Whinston, Electronic Commerce: A Manager's Guide (Reading, MA: Addison-Wesley, 1997).

[4] T. A. Powell, Web Design: The Complete Reference Second Edition, McGraw-Hill Companies, Inc, USA, 2002.

[5] G. P. Schneider, e-Commerce, Massachusetts: Course Technology-Thomson Learning, Inc., Canada, 2002.

[6] Solanki, A Wide Spectrum Language for Designing Web Services, Software Technology Research Laboratory, Leicester, UK, 2001.

[7] F. N. Udechukwu, Survey of Small and Medium Scale Industries and their Potentials in Nigeria, A Seminar on Small and Medium Industries Equity Investments Scheme (SMIEIS) a Publication of CBN Training Centre, Lagos, Central Bank of Nigeria, 2003.

[8] E. Turban, D. King, J. Lee, and D. Viehland, Electronic Commerce: A Managerial Perspective, New Jersey: Pearson Prentice Hall, 2004.

[9] M. Ruzzier, R. B. Hisrich and B. Antoncic, SME Internalization Research: Past, Present, and Future, Journal of Small Business and Enterprise Development 13(4):476-497, 2006.

[10] D. J. Pare, Does this site delivers? B2B e-Commerce Services to Developing Countries, Information Society 19:123-134, 2003.

[11] W. Poh-kam, Global and National Factors Affecting Diffusion of e-Commerce in Singapore, Information Society 19:19-32, 2003.

[12] A. Molla and R. Heeks, Exploring e-Commerce Businesses in developing country, Information Society 23:95-108, 2007.

[13] W. Jen-Her and H. Tzyh-Lih, Developing e-Business Dynamic Capabilities: an Analysis of e-Commerce Innovation from $I-, M$-, to U-Commerce. Journal of Organizational Computing and Electronic Commerce, 18: 95-111, 2008.

[14] M. Kapurubandara and R. Lawson, Availability of e-Commerce Support for SMes in Developing Countries, The International Journal of Advances in ICT for Emerging Regions, 01(01): 3-11, 2008.

[15] http://www.digitsmith.com/e-Commerce-definition.html (October 23, 2009)

[16] e-Business Guide for SMEs available at http://ec.europa. eu/enterprise/e-bsn/ebusiness-solutions guide/docs/ eBusiness_Guide_for_SMEs.pdf. (October 24, 2009)

[17] A. Scupola, SMEs e-Commerce adoption: perspective from Denmark and Australia, Journal of Enterprise Information Management, 12(1):152-166, 2009.

[18] C. L. Iacovou, I. Benbasat and A. S. Dexter, Electronic Data Interchange and Small Organizations: Adoption and Impact of Technology, MIS Quarterly, 19(4):465-485, 1995.

[19] K. Kuan, and P. Chau, A perception-based model of EDI adoption in small businesses using technologyorganization-environment framework, Information and Management, vol.38, pp. 507-521, 2001.

[20] A. Scupola, The Adoption of Internet Commerce by SMEs in the South of Italy: An Environmental, Technological and Organizational Perspective, Journal of Global Information Technology Management, 6(1): 51-71, 2003.

[21] T. Daugherty and B. B. Reece, The adoption of persuasive Internet communication in advertising and public relations curricula. Journal of Interactive Advertising, 3(1), 2002.

[22] L. Arendt, Barriers to ICT adoption in SMEs: how to bridge the digital divide? Journal of System and Information Technology, 10(2):98-108, 2008.

[23] J. Liebenau, G. Harindranath and G. B. Özcan, SMEs Productivity and Management: A Research Agenda for ICT and Business Clusters, 2004. 
[24] S. Chirasirimongkol and W. Chutimaskul, Information Technology for Thai Leather SME Development, Fourth International Conference on e-Business, Bangkok, Thailand, 26.1-7, 19-20 November 2005.

[25] J. Yang, Small and Medium Enterprises (SME) Adjustments to Information Technology (IT) in Trade Facilitation: The South Korean Experience, 2009.

[26] Hauser, A qualitative definition of SME, http://www.oecd. org/dataoecd/32/14/35501496.pdf. (September 5, 2009)

[27] K. Hak-Su, Small and Medium Enterprises and ICT, http:// www.unapcict.org (September 6, 2009) 